\title{
Are entrepreneurial cultures stable over time? Historical evidence from China
}

\author{
Sonja Opper $^{1}$ - Fredrik N. G. Andersson ${ }^{1}$
}

Published online: 29 April 2018

(C) The Author(s) 2018. This article is an open access publication

\begin{abstract}
Are entrepreneurial cultures stable over time? In this paper, we use historical measures of the outgrowth of entrepreneurial culture in China and test whether these correlate with entrepreneurial activities today. We employ provincial panel data from China documenting the regional distribution of entrepreneurial activities during the Ming Dynasty (1368-1644) and the Qing Dynasty (1644-1912) and private firm activities in post-reform China (1992-2012). Our study finds a significant association between the regional distribution of historical and current measures of entrepreneurship, supporting (1) the long-term stability of underlying regional cultural differences; and (2) the adaptability of entrepreneurial activities to changing institutional arrangements and relative payoff structures. These results are robust to numerous alternative explanations, including geography, agglomeration advantages, education, and technology. Our findings suggest that government efforts to encourage new business ventures - if they are to have more than short-term effects- will need to take into account local cultural norms.
\end{abstract}

Keywords Entrepreneurship · Entrepreneurial culture · Long-term stability · Private firms $\cdot$ China

JEL $\mathrm{L} 26 \cdot \mathrm{M} 13 \cdot \mathrm{N} 35 \cdot \mathrm{P} 31 \cdot \mathrm{R} 11$

With half of China's 12 million private firms located in five of the country's 31 provinces-notably in the eastern provinces of Jiangsu, Guangdong, Shanghai,

Sonja Opper

Sonja.opper@nek.lu.se

Fredrik N. G. Andersson

Fredrik_n_g.anderssen@nek.lu.se

1 School of Economics and Management, Lund University, Scheelevägen 15B, 22007 Lund,

Sweden 
Zhejiang, and Beijing - China's post-transition economy is characterized by pronounced within-country variation with respect to private firms (Annual report on the non-state-owned economy in China, 2015; Hoskisson, Eden, Lau, \& Wright, 2000). Given comparable economic and political starting conditions at the outset of the country's reforms, and rather uniform national institutions, formal institutional explanations struggle to fully explain these regional imbalances and the large variation in entrepreneurial activity in China. Furthermore, standard explanations focusing on endogenous agglomeration advantages also fail to provide compelling answers (DellaPosta, Nee, \& Opper, 2017). Private firms neither co-located with established state-owned enterprises (SOEs) or collective firms, nor simply followed the inflow of foreign direct investments (FDIs) in the 1980s and 1990s. Private firm location is also not closely correlated with the initial regional economic strength at the outset of the economic reforms. In fact, the reemergence of a private firm economy was most pronounced in rural or exurban China, specifically in regions that had been notoriously neglected by central planners (Whiting, 2000).

In this study, we shift attention to the question of whether different local culturesevidenced by differences in the regional supply of entrepreneurial talent - are associated with the uneven revival and development of private firms in China, and their continuing uneven spatial distribution. "Entrepreneurial cultures"-defined as a set of shared beliefs, norms, and expected behavior transmitted and internalized over multiple generations - have long been associated with regional differences in firm development. There is evidence linking distinct cultural components with management strategies, such as technology alliances (Steensma, Marino, Weaver, \& Dickson, 2000) and rates of innovation (Shane, 1993), though Singh (2007) has cautioned that the impact of culture on strategy may be somewhat limited. A closer association is observed for macro phenomena such as locational choices for economic activities (Hayton, George, \& Zahra, 2002; Liñán \& Fernandez-Serrano, 2014; Pinillos \& Reyes, 2011; Zelekha, Avnimelech, \& Sharabi, 2014). Cross-regional studies conducted in the West confirm these cross-country results, providing some confidence that cultural variation also matters at the sub-country level (Davidsson \& Wiklund, 1997; Fritsch \& Wyrwich, 2014; Hayton et al., 2002). What is unclear is whether cultural differences persist, such that certain countries (or regions) enjoy lasting advantages (or disadvantages) in developing private enterprises (Ahlstrom, Young, Chan, \& Bruton, 2004; Landes, 1998). Or, is the opposite true: cultural differences are less enduring, and perhaps convey less advantage than is commonly thought (Ahlstrom \& Wang, 2010)?

In this paper, we explore the stability of differences in local entrepreneurship over time. Note that we are not attempting to trace or identify the "origin" of distinct local entrepreneurial cultures (as discussed in Huo \& Randall, 1991; see also Kwon, 2012). We are also not claiming to establish a causal link between distinct types of culture (as in the individualism vs. collectivism framework, for instance) and entrepreneurial outcome. Rather, we build on Baumol's theory of entrepreneurial talent allocation (Baumol, 1990; see also Murphy, Shleifer, \& Vishny, 1991) to develop a test of the long-term stability of regional entrepreneurial cultures and their impact on withincountry variation in entrepreneurial activities.

Our testing strategy is necessarily indirect. We cannot directly measure regional cultures dating back hundreds of years, at least in terms of established measures. Instead, we use historical measures of the outgrowth of entrepreneurial culture and 
observe whether these correlate with entrepreneurial activities today. Two core assumptions guide our research design. First, "entrepreneurs" are not narrowly defined as individuals starting a firm, but, rather, as "persons who are ingenious and creative in finding ways that add to their own wealth, power, and prestige" (Baumol, 1990: 897). Entrepreneurial activities (i.e., those advancing an individual's wealth, prestige, and power) can involve either productive start-up investments or socially unproductive rentseeking activities. Along this definition, a local entrepreneurial culture is particularly rich in people who are "creative in finding ways that add to their own wealth, power, and prestige." Second, we assume that people are drawn to specific types of entrepreneurial activities by institutional arrangements - the local rules and laws - and the emergent relative payoff structures (Baumol, 1990; see also Acemoglu, 1995, for a formal model endogenizing the payoff structures). Building on these two assumptions, and utilizing historical measures and processes (Peng, Ahlstrom, Carraher, \& Shi, 2017) we expect regions with high concentrations of entrepreneurial activities in the past to experience a faster recovery of the private firm economy once current institutions reward private investments.

Our empirical strategy employs two historical measures (outgrowths) of entrepreneurial culture. First, following Baumol's (1990) seminal contribution on productive and unproductive entrepreneurship - and hence taking his narrative to a quantitative test - we use the regional origin of high-level palace officials during the Ming Dynasty (1368-1644) as a proxy for historical talent distribution during pre-industrial times. Second, we use the number of merchant guilds in each region during the Qing Dynasty (1644-1912) as a proxy for the outgrowth of entrepreneurial culture during the early phase of industrialization. Our empirical results show an intriguingly similar distribution of entrepreneurial activity over time. By and large, we observe that provinces that have been entrepreneurial during the Ming and Qing dynasties tend to be also entrepreneurial in modern times, with only the form of entrepreneurship changing over time.

Our contribution is threefold. First, our study contributes to two theoretical strands in the entrepreneurship literature. We offer a long-term test of Baumol's theory of entrepreneurial talent allocation, showing that the distribution across provinces of local pools of entrepreneurs in China is relatively stable over extended time periods. Our findings also feed into theories of institutional change and underscore the need for a culturally embedded understanding of development trajectories. Empirically, the use of historical measures of the outgrowth of entrepreneurial activities offers a novel way to study the persistence of entrepreneurial cultures over time. Finally, our study has some practical implications, specifically for public policy makers but also for private investors. If entrepreneurship does indeed depend on deep-rooted cultural values transmitted over generations, it is questionable whether large-scale infrastructure investments and the import of capital and knowledge provide the right tools to incentivize entrepreneurship in less-developed regions and aid in an economy's development (Matthews, 2017; McCloskey, 2010).

The remainder of the paper is structured as follows. Next, we review how institutions and values contribute to the emergence of entrepreneurial cultures and how these affect entrepreneurial activities. Then, we introduce our measures of outgrowths of entrepreneurial culture during the Ming and Qing Dynasties. The following section details our data and methods, followed by the study's results and a concluding discussion. 


\section{Theory and proposition}

\section{Long-term stability of entrepreneurial culture}

Conceptually, culture has long been perceived as a factor pertaining to cross-national and interregional differences in economic activity and firm management. Observations by Weber (1904/2006) and Schumpeter (1912/1934) have inspired a stream of research presenting culture as a factor likely explaining some of the differences in economic activities and new venture creation, both across countries (Ahlstrom \& Wang, 2010; Landes, 1998; Liñán \& Fernandez-Serrano, 2014; Pinillos \& Reyes, 2011; Zelekha et al., 2014) and regions (Beugelsdijk, 2010; Davidsson \& Wiklund, 1997). Differences in regional cultures have recently also gained recognition in research on China's economic and business development (Gong, Chow, \& Ahlstrom, 2011). Kwon (2012) confirmed, in a comparison between the regions of Shenzhen and Taiyuan, stark differences in work-related values.

The stability of distinct cultures, however, has remained outside of the analytical focus. Inspiration to study the long-term endurance of discrete cultures has come from work on evolutionary perspectives on human behavior, and has emphasized the "hardwired" nature of cultural values (Pagel, 2012; Richerson \& Boyd, 2005; Richerson \& Christiansen, 2013). Culture, defined as "information capable of affecting individuals' behavior that they acquire from other members of their species through teaching, imitation, and other forms of social transmission" (Richerson \& Boyd, 2005: 5), is closely linked, here, with different systems "of rules, beliefs, norms, and organizations that together generate a regularity of (social) behavior" (Greif, 2006: 30). These variations in incentives, beliefs and values (Jiao, Harrison, Dyball, \& Chen, 2017) are very important and lead to observable group-specific preferences for (and sometimes against), certain courses of action that become accepted parts of local cultures (McCloskey, 2010; Peterson \& Seligman, 2004).

But, are local incentives and beliefs sufficiently stable to shape local entrepreneurial cultures over extended periods of time? And as such, do individuals in some regions have a greater appetite for entrepreneurial activities than those in other regions? That formal institutions influence the relative payoff structure of different professions is well established (North, 1990). They define the profit rate and relative attractiveness of different courses of action and thereby channel entrepreneurial action in either productive or unproductive (rent-seeking) activities (Baumol, 1990). What is less frequently discussed is the fact that these incentives, once established, have the tendency to become stable over time. Acemoglu (1995) proposed a formal model showing that, once institutions reward certain activities, they become endogenous to the extent that it becomes rational for the majority of the population to direct their efforts toward these activities. History becomes a predictor of future talent allocation. That is, once institutions reward rent-seeking activities, there will be a toll on turning toward productive activities. Conversely, once institutions reward productive activities, rent-seeking becomes a losing proposition. From a dynamic perspective, agents can therefore be caught either in a "rent-seeking" or in a productive steady-state equilibrium. It is easy to see that, over time, the stability of reward structures will nurture the rise of distinct cultures.

However, it is not just institutions that matter. Social validation also plays a powerful role in steering human behavior toward either productive or unproductive activities. 
Through reward and punishment of favored and sanctioned behavior, distinct choiceshere, career paths - become either attractive or unattractive (Richerson \& Boyd, 2005). Whether social validation has its roots in religious beliefs, philosophical traditions, kinship and community rules, or state policies is a separate consideration; what matters to the individual entrepreneur (or would-be entrepreneur) is to find social approval and status. Being recognized as someone pursuing a legitimate and honorable career is a powerful factor in explaining the popularity of certain professions. The risk of being stigmatized and ostracized, in contrast, steers individuals away from low-status activities. With social validation being shared and transmitted through a process of group learning and imitation repeated over multiple generations - a mechanism emphasized both in the social sciences' new institutionalism and in theories of the cultural evolution of human behavior - social beliefs oftentimes become stable over extended periods of time and are rarely changed. These theoretical arguments are consistent with a casual observation that virtually all countries share: people in some regions are generally perceived as being particularly entrepreneurial, whereas those in other regions seem to lack entrepreneurial talent. While cultural differences are necessarily more pronounced across countries, due to stronger differences in politics and history, "it is reasonable to expect that countries can be segregated into culturally homogenous regions" (Hayton et al., 2002: 37). In fact, various cross-country and cross-regional studies have confirmed regional cultural variation, both in Western as well as in Asian cultures (Davidsson \& Wiklund, 1997; Kwon, 2012; Thomas \& Mueller, 2000).

\section{The dynamics of entrepreneurial talent allocation}

The stability of "entrepreneurial cultures" (i.e., cultures that reward the accumulation of power and wealth) does not imply the long-term constancy of talent allocation. The outgrowths of distinct beliefs and behavioral patterns change gradually, with social, economic, and institutional development changing the opportunity space individuals face (Turchin, 2013). Baumol (1990: 3) emphasized, in his allocation theory of entrepreneurial talent, that it is likely that the way "the entrepreneur acts at a given time and place depends heavily on the rules of the game - the reward structure in the economy - that happen to prevail." Baumol (1990) extended Schumpeter's definition of the entrepreneur considerably, ${ }^{1}$ as he identified individual traits and goal orientation, rather than specific activities, as the defining features of "entrepreneurship." In his theory, as noted above, entrepreneurs are "persons who are ingenious and creative in finding ways that add to their own wealth, power, and prestige" (Baumol, 1990: 897). The specific route of action that entrepreneurs pursue is guided and shaped by economic institutions - the rules of the game (North, 1990) - that define the opportunity space and relative payoff structure of different activities. Exogenous shifts in the institutional setup can then lead to a major reallocation of entrepreneurial talent, shifting either from rent-seeking activities toward productive activities or vice versa.

\footnotetext{
${ }^{1}$ Schumpeter (1912/1934: 66) limited entrepreneurial activities to what Baumol would later define as "productive entrepreneurship." More specifically, Schumpeter defined entrepreneurs as individuals pursuing "new combinations" in the form of any one of the following: (1) the introduction of new products, (2) the implementation of new production methods, (3) the opening of new markets, (4) the conquest of a new source of supply, and (5) the creation of a new organization of any industry.
} 
Yet, it is not only changes in the formal institutional environment that influence entrepreneurial talent (re)allocation and encouragement. A revaluation of social beliefs amplifies the effect of changing institutions. McCloskey $(2006,2010)$ highlighted the importance of social beliefs and validation in her in-depth study of the role of the bourgeoisie and their sponsors in the rise of modern economic growth. McCloskey (2010) made the case that it was not institutional change alone but also the shift in public perception and beliefs that enabled the bourgeoisie to venture into new professions and to become capitalists. Similarly, Mokyr (2017) saw the European Enlightenment and changes in culture (particularly how innovativeness and experimentation were encouraged) as a necessary precursor for innovation, the rise of technology, and ultimately the industrial revolution. Here, it is the changing beliefs regarding the free and liberal exchange of ideas among the intellectual elite that paved the way to a new level of economic growth. Briefly, it is a tandem of local incentives and social beliefs that, over the long run, shapes entrepreneurial cultures and talent allocation.

Casual accounts of entrepreneurship in China underscore the likely persistence of local culture over time. Although, at the outset of economic reforms in China in 1978, all regions started out from comparable levels of economic (under-)development and an overwhelming dominance of state-owned production, the emerging pattern of postreform entrepreneurship quickly displayed strong regional inequalities. These inequalities have continued, and provinces along the east coast had between 1.5 and 4 times as many private firms per capita as the average Chinese province in 2012 , while inland provinces such as Qinghai and Tibet had approximately half the number of private firms per capita as the average province (see Fig. 1).

Thus, our core proposition is as follows:

Proposition 1 Chinese regions that have historically displayed a high concentration of entrepreneurial activities enjoy comparative advantages in the recreation of a postreform private firm economy, once the institutional constraints of the old socialist regime have been lifted and the relative payoff structure starts rewarding productive entrepreneurship.

\section{From palace official and merchant to capitalist}

Baumol's definition of what makes an entrepreneur opens up novel-yet untappedopportunities to systematically explore the long-term stability of local entrepreneurial cultures and talent pools throughout time, as the identity of the entrepreneur is not linked to modern forms of industrial production characterized by the Schumpeterian innovation types. This brings preindustrial activities to the fore of the analysis, allowing for much longer time horizons in the examination of national and local differences of entrepreneurial activities and their path-dependent evolution throughout time, while avoiding the need to control for agglomeration effects - as, for instance, in longitudinal firm-level studies. In this study, we focus on occupational choices in both preindustrial times and early industrialization to test the long-term stability in the regional distribution of entrepreneurial talent pools and their effect on the rise of modern entrepreneurship in China.

So, which activities attracted the "ingenious and creative" entrepreneurs of their time? The Ming Dynasty (1368-1644) was a period when, as in Europe before the great 


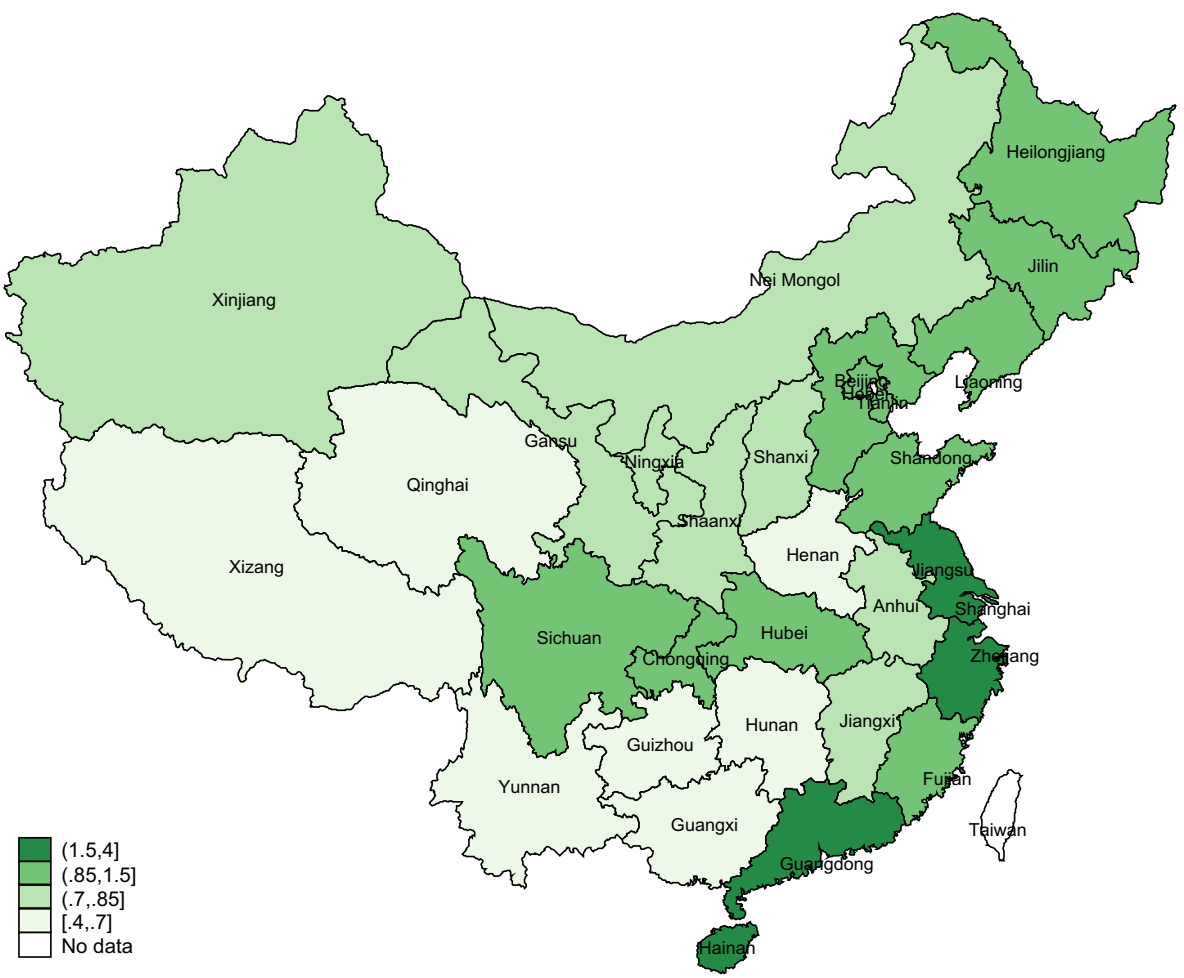

Fig. 1 Regional distribution of private firms, 2012. Note: A darker (lighter) shade signals a higher (lower) concentration of private firms

reformation (North, 1990), private property and investments were not safe and could be confiscated whenever the sovereignty needed to refill its state coffers. Any type of commercial activity was therefore very unattractive, given the relatively high uncertainties associated with private investments. In contrast, the career of an imperial scholar-official offered the promise of tremendous power and wealth. No other position in the army, crafts, or guilds could generate comparable prestige and remuneration, not only for the officeholder but also for their entire kin - it often provided wealth and security over several generations (Elman, 2013; Ho, 1962). In this sense, "government service was by far the most honorable and, in every sense, the most worthwhile occupation; and the examinations played a large part in determining the composition of the elite" (Miyazaki, 1976: 7). Just as in the "rags-toriches" tale of the successful entrepreneur of modern times, the attainment of the highest titles (the so-called jinshi degree) awarded to those literati presented to the emperor for appointment as government official (Elman, 2013: 102) lead to an individual's elevation in terms of both economic and social status (Ho, 1962: 43; see also Miyazaki, 1976).

Importantly, under the Ming Dynasty, the career of a scholar-official became accessible to the entire population as it was based on merit. That is, a civil service career was no longer restricted to members of the aristocracy but was open to anybody who was willing to prepare for and succeeded in a series of highly competitive civil service examinations. All citizens, including once disregarded professional groups such as merchants and artisans, were eligible to participate in the various examination stages that eventually lead up to the highest palace degrees (Elman, 2013). Talented young people who could not afford personal advisors 
enrolled in charitable schools that helped to prepare local talents for the examinations. It is also notable that the Ming Dynasty was the last period in which the award of the highest palace degrees was performance based, and not governed by a quota system to equalize the representation of regions in the imperial bureaucracy, which made the regional distribution of candidates advancing to these high-level positions a market-based outcome. Briefly, the career of a palace official was not only the most rewarding activity any "entrepreneur" following Baumol's definition of a person "ingenious and creative in finding ways that add to their own wealth, power, and prestige"-would turn to. It was also a socially highly valued profession. Palace officials were the "entrepreneurs" of their time.

With the end of the Ming Dynasty and the transition to the Manchurian rule of the Qing Dynasty, commercialization became a core interest of the state (Giersch, 2014; Min, 2013). The profits to be harvested were tremendous, turning commerce and trade quickly into a strategy for empire building, especially in the border regions. Longdistance trade, in particular, was promoted in order to generate state revenue, partly through trade monopolies but also through close relations with merchants. To accelerate the establishment of long-distance trade routes, merchants were even free to use the postal road system in support of interprovincial trade (Giersch, 2014). Wealthy merchants could reap tremendous profits and accumulate immense resources: they invested in mines, started manufacturing and transport enterprises, and established pawnshops and banks to facilitate long-distance trade. Clearly, the institutional innovations of the Qing governments paved the way for a massive reallocation of resources and talent.

By the time "the tide of commerce moved eastward" and "people were drunk with profit and venerating almighty mammon" (Min, 2013: 171), the new merchant class had already benefited from an enhanced social status, thanks to their access to the imperial court during the Ming Dynasty. Social acceptance of merchants as a new elite group was further amplified by their widespread philanthropic activities supporting the poor, in the form of educational efforts as well as relief support during natural disasters. Doing business while still demonstrating Confucian ethics made the sudden elevation of the new class not only socially acceptable but desirable (Min, 2013). Indeed, doing business became a highly lucrative and respected alternative to the life of a scholarofficial. "Born in the 19th century, the so-called year of industrial competition, we businessmen are really highly respected. We have the most energetic spirit and the most highly developed abilities in the world, and can act as a driving force for mankind. Nothing else except commerce has such value" (translated and cited in Min, 2013: 166). Notably, the narrative of the merchant class during the Qing Dynasty is similar to McCloskey's (2010) account of the changing esteem and appreciation of the bourgeoisie that was required for the latter to play its role in the industrial revolution.

Building on these brief institutional narratives and on Baumol's definition of entrepreneurship, provincial success rates in achieving jinshi degrees under the Ming Dynasty and the regional distribution of merchants in the Qing Dynasty provide us with historical measures of entrepreneurial activity. By testing for a positive association between these historical measures and entrepreneurship in post-reform China, we gain two important insights: (1) a positive correlation among these three different entrepreneurial activities implies the longitudinal stability of entrepreneurship and underlying local cultures; and (2) confirmation of a positive correlation between these professional choices corroborates Baumol's claim that entrepreneurial talent allocation shifts with the relative payoff structures and opportunities, but remains locally relatively stable. 


\section{Methodology}

\section{Data collection}

We relied on aggregate provincial data retrieved from publicly available sources. For economic data of the post-reform period, we used data from the Chinese National Bureau of Statistics published in national statistical yearbooks and specialized yearbooks documenting the development of the private firm economy (Annual report on the nonstate-owned economy in China, various years). Data on jinshi exams came from China's imperial archives covering success in the civil service examinations (Ho, 1962). These data are highly reliable and cover the entire country. ${ }^{2}$ Data on merchant guilds came from MollMurata (2008). Source information for all control and auxiliary variables is provided in Appendix Table 6. Overall, our provincial panel data covers the period from 1992 to 2012. Earlier provincial data is not available for private firms. Our analysis is, thereby, limited to a more advanced stage of the economic reforms; however, we still cover the entire period from the introduction of the socialist market economy in 1992 until present times. It is also noteworthy that there were only 139,600 private firms in China in 1992 compared to $10,850,000$ firms in 2012. Our sample period, therefore, captures the period when most of the expansion of private firms took place.

\section{Variables}

\section{Dependent variable}

Our dependent variable is the number of private firms per capita registered in each province. Our focus on aggregate measures of private firm concentration is consistent with our interest in understanding a region's ability to develop a private firm economy at large, and the fact that relatively large geographical areas are likely to exhibit a similar culture. At the same time, cross-provincial comparisons provide sufficiently large identifiable cultural differences to conduct meaningful statistical tests. While we acknowledge the risk that our geographical units are too large, we posit that the effect on our analysis of using a different approach would be to reduce the likelihood of finding any effect of culture. Any identification of a significant finding would, therefore, be downward and not upwards biased.

Two central advantages of China's company statistics are that self-employed individuals do not register under the same legal status as private companies (instead registering as "individual household enterprises") and former SOEs operating as partly or fully private-owned companies are recorded under a distinct category of joint stock and limited liability firms. A firm qualifies as being private if the founder is a natural person or if one or multiple natural persons holds the majority of shares. Furthermore, for inclusion within China's statistics of private companies, the firm must employ a minimum of eight salaried workers. We are, therefore, confident that the total firm

\footnotetext{
${ }^{2}$ In contrast, data on historical economic performance are limited and inconsistently recorded across the country. A study on the extent of marketization in imperial China by Shiue and Keller (2007), for example, had to rely on scattered and incomplete data on transport costs, grain prices, and trade volumes for various prefectural markets.
} 
count used in this analysis comes relatively close to the idea of someone pursuing - in Baumol's definition - productive activities to create wealth and status, rather than someone just being pushed into self-employment to avoid poverty or unemployment.

\section{Explanatory variables}

The main explanatory variable in the model is either the number of jinshi degrees per capita during the Ming Dynasty or the number of merchant guilds in the Qing Dynasty. The historical jinshi data are collected from Ho (1962), who recorded the total number of jinshi registered for the period 1371-1644, covering almost the entire Ming Dynasty period. These records include nearly 23,000 individuals for whom geographic origin data is available, representing more than $90 \%$ of all jinshi degrees awarded during the Ming Dynasty. Population data (also from Ho, 1962) are estimates of the average population during the Ming Dynasty, based on population censuses conducted in 1393 and 1787, as well as secondary sources detailing changes in population during the 15th and 16th centuries. These data reflect the provincial boundaries of the Republic of China in the first half of the 20th century; several of these regions include the territory of two or more modern-day provinces, resulting in 22 provinces in our data set, compared to 31 current provinces in the People's Republic of China. ${ }^{3}$ For consistency with the availability of these key data, all other variables were matched to the same provincial boundaries. For four provinces, all on the periphery of imperial China, no jinshi data are available as they were not part of the Ming territory. These provinces have been assumed to have zero jinshi degrees. In the estimations, we included a dummy variable for these provinces to ensure that this data interpolation did not affect our results. ${ }^{4}$

We explored the question of whether distance to the capital could have influenced the allocation of jinshi degrees. Since imperial exams were conducted in the capital, it would be reasonable to assume that travel distance might have influenced examination participation and corresponding outcomes. Closer examination of the spatial distribution of jinshi degrees, however, does not support this view. Figure 2 shows that provinces as far away as Fujian in the south had the highest examination success rates per capita. Almost all other provinces with weaker jinshi success were within closer reach of Beijing (indicated by the dashed circle).

There are no national records available for the number of merchants active during the Qing Dynasty. Instead, we use guilds to measure the number of merchant guilds per capita that had branch offices in other provinces, which we use as a proxy for merchants involved in the more lucrative long-distance trade (Moll-Murata, 2008). As previously discussed, this trade not only promised the greatest profits from arbitrage but was also an important part of the empire-building strategy of the Qing Dynasty.

The regional distribution of guilds is similar to the spread of jinshi, with a high concentration in coastal provinces such as Zhejiang and Fujian and inland provinces such as Jiangxi and Hunan (see Fig. 3). There are also some differences, such as the

\footnotetext{
${ }^{3}$ The differences between republican and modern provinces are as follows: Beijing, Tianjin, and Hebei are aggregated into "North Zhili," "Liaoning" includes also Jilin and Heilongjiang, "Jiangsu" includes Shanghai, "Guangdong" includes Hainan, "Sichuan" includes Chongqing, and "Shaanxi" includes Gansu and Ningxia.

${ }^{4}$ These provinces are Inner Mongolia, Tibet, Qinghai, and Xinjiang. The results are robust to dropping these provinces instead, or assuming a value of zero rather than the minimum from the other provinces. (Results available from the authors on request.)
} 


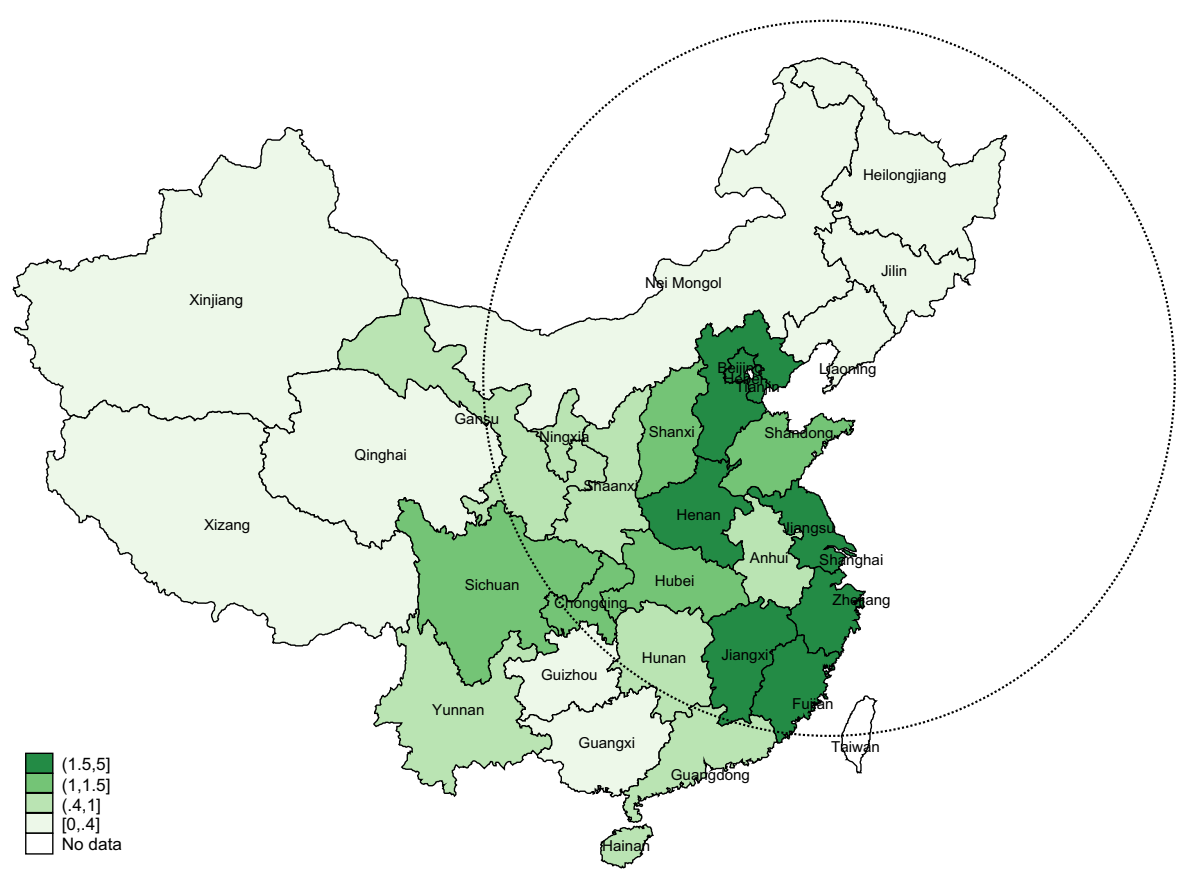

Fig. 2 Regional distribution of jinshi degrees during the Ming Dynasty. Note: A darker (lighter) shade signals a higher (lower) concentration of jinshi degrees

weaker concentration of guilds around Beijing compared to that of jinshi degrees. It is of course only natural to expect some variation in the distribution over time. The general pattern, however, remains similar across the centuries.

\section{Analysis}

Given the exploratory nature of our study, we began our analysis with a principal component analysis (PCA) validating the shared cultural component connecting our variables of interest. Our approach is in line with other exploratory studies that use this statistical method to first confirm or - at a minimum - support the underlying concept when introducing a novel measure into the literature (Tabellini, 2010). For the second step, we shifted to a panel data analysis to explore the link between modern and historical forms of entrepreneurship.

\section{$P C A$}

Due to the novelty of our key variable of jinshi degrees, we began with a validation strategy to confirm the soundness of our measures of entrepreneurial activity. To this end, we needed to ascertain that regional success rates in jinshi examinations and the regional distribution of guilds are not simply a reflection of state capacity and modern socioeconomic development, but that they capture, following Baumol's definition, the essence of entrepreneurship, or, more broadly, an entrepreneurial culture. 


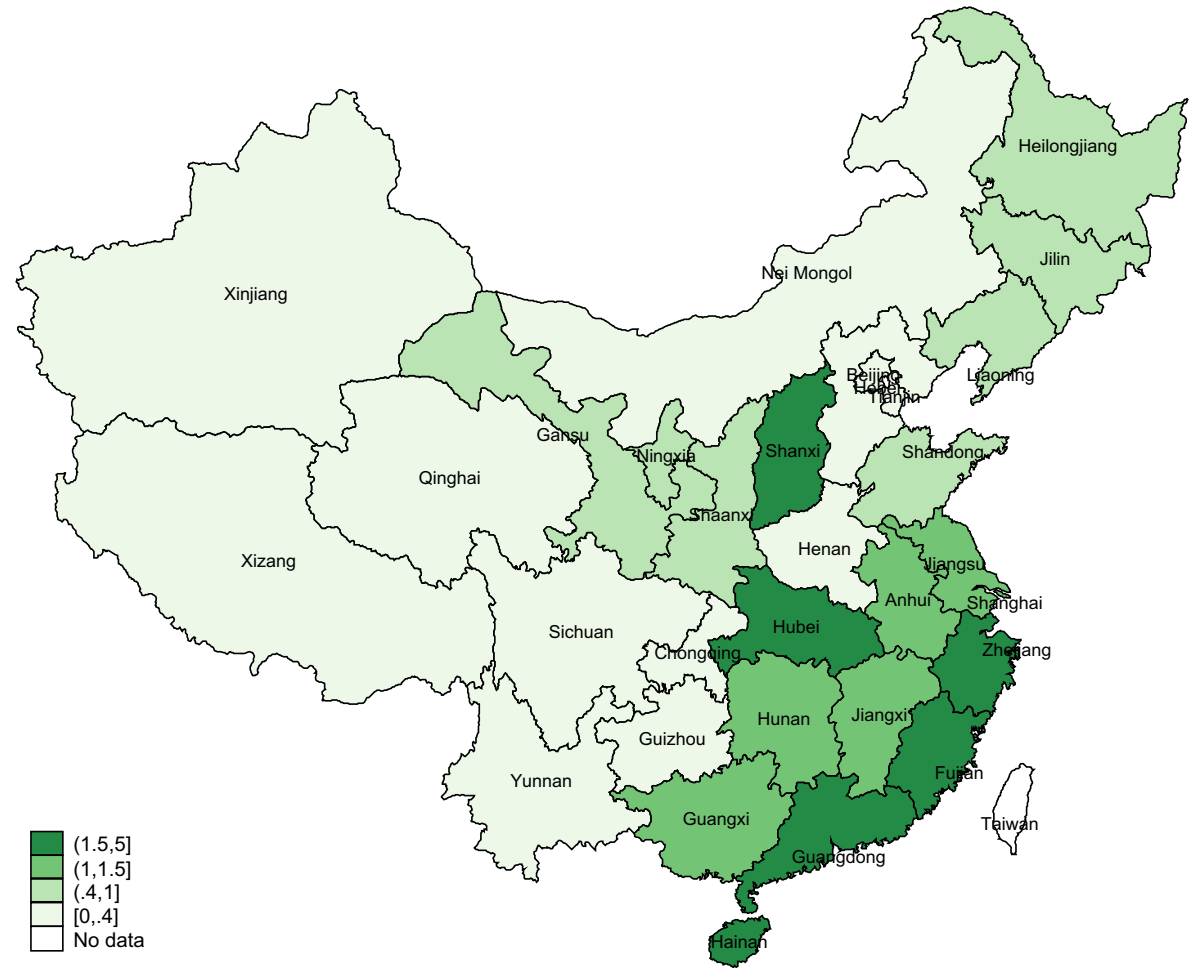

Fig. 3 Regional distribution of guilds during the Qing Dynasty. Note: A darker (lighter) shade signals a higher (lower) concentration of guilds

PCA is a more advanced method with which to analyze the correlation structure among a set of variables, compared to, for example, a correlation table. Technically, PCA reduces a set of variables into a few common components (dimensions) and tests how each variable relates to these common dimensions (Jolliffe, 2002). This allows us to identify if jinshi is related to a cultural dimension, state-capacity dimension, or modern socioeconomic dimension.

\section{Panel data analysis}

For a more detailed analytical exploration of the stability of entrepreneurial activities over time, we relied on a set of panel data estimations. The dependent variable in our model is the number of private firms per capita in each province. To control for potential confounding effects that may influence firm allocation, we introduced a wide set of additional explanatory variables covering state capacity, socioeconomic development, and geography - partly also included in the PCA. Our baseline model is given by:

$$
\text { Entrepreneurship }_{i t}=\alpha+\beta_{1} \text { culture }_{i t-1}+\beta_{2} \text { state }_{i t-1}+\beta_{3} \text { socioecon }_{i t-1}+\beta_{1} \text { geography }_{i}+\mu_{i}+\varepsilon_{i t}
$$

where $i$ denotes provinces, $t$ denotes time, and $\mu_{i}$ is a province-specific random effect that controls for other non-time-varying factors affecting entrepreneurship not included in the model. 
We used random effects rather than fixed effects because several of our explanatory variables are non-time-varying and, therefore, preclude us from using fixed effects. A potential complication with random effects panel data models is that they require the explanatory variable and random effects to be strictly exogenous. In the robustness section, we also estimated models without any random effects and a cross-sectional model. The results from these robustness tests confirmed our main results. Given our interest in the spread of private firms across China's provinces, we normalized our data by the year cross-sectional average. By normalizing the data, we also indirectly controlled for common time shocks and we did not need to include time effects in the estimations. Further, we focused on the long-term trend movements and removed short-term variations by using three-year averages. The first three-year period covered 1992 to 1994 and the last three-year period covered 2010 to 2012. The use of longer averages, such as four years, did not change the results. All historical and geographical data were constant over time. Modern socioeconomic control variables, however, did vary over time. All time-varying variables are likely to have a lagged effect on private sector development, which is why we lagged them by one time-period. ${ }^{5}$

We extended our model along two dimensions. First, to incorporate the idea that institutions shape the relative payoff structure and, therefore, should have an impact on local entrepreneurial talent allocation, we split the sample into two subsamples representing the pre- and post-2003 period. This is because virtually all legal institutions supporting and protecting entrepreneurial activities were absent or enforced weakly during the first reform period. Private firms remained stigmatized and could not register their activities until 1987. Any form of surviving entrepreneurial culture was, therefore, initially at odds with the formal institutional structure continuing to prioritize the development and corporatization of traditional SOEs into modern companies. Private firm status, property security, and expected payoffs only increased significantly from 2004, when the national government amended its constitution to give private firms equal status with non-private forms of ownership (Nee \& Opper, 2012). We, therefore, expected that the association between the earlier outgrowth of entrepreneurial culture and private firm allocation would be stronger in the second subsample.

In the second set of models, we included two interaction terms to test whether the association between historical and modern entrepreneurial activity was enhanced or reduced by the quality of state capacity and the inflow of foreign entrepreneurial cultures. State capacity is closely linked to the enforcement of formal institutions and can, thereby, critically affect expected payoffs. With reforms starting out in China's coastal regions, and the reform willingness of provincial governors and party secretaries differing specifically in the first period of reforms, there could be significant interactions with local entrepreneurial cultures (Ahlstrom, Young, Nair, \& Law, 2003).

A second type of interaction could result from cultural mixing, associated with the rapidly growing inflow of FDIs. China has-like many other transition and emerging economies - heavily utilized FDIs as a strategy to stimulate the country's technological catch-up process (Steensma, Tihanyi, Lyle, \& Dshanaraj, 2005), but this also had consequences for local institutional quality (Long, Yang, \& Zhang, 2015). As early as 1979, China's government launched preferential treatment policies for foreign investors, thereby

\footnotetext{
${ }^{5}$ For all time-varying variables, our results were largely robust to the choice of lag length. Results are available from the authors on request.
} 
accelerating the inflow of FDIs (Lau \& Bruton, 2008), leading to spillover effects in terms of employment growth, technological innovation, and productivity growth (Sun, 2011). However, FDIs not only provide novel technologies and investments: with a growing inflow of FDIs, recipient countries and regions often also face a dilution of their indigenous culture and novel intercultural differences, as well as conflicts that can reduce creativity and innovative activities, even if individual players are not directly involved in conflict situations but are only indirectly exposed (Chua, 2013). Exposure to foreign culture was modeled using real FDIs per capita. Transition and emerging economies often utilize FDIs as a strategy with which to stimulate the country's technological catch-up process (Steensma et al., 2005), which makes FDI a good proxy for our purposes.

\section{Results}

\section{PCA}

Since it is our interest to show that jinshi, guilds, and modern private firm activities all share a distinct and durable local cultural dimension and are not merely defined by state capacity or socioeconomic predictors, we combined our core variables of interest with a standard set of variables commonly believed to influence entrepreneurial activities. If entrepreneurial culture is stable over time, we would expect to find that jinshi, guilds, and private entrepreneurship share high loadings on the same component (signifying underlying cultural traits), but less so with other socioeconomic variables reflecting non-entrepreneurial activities.

To proxy entrepreneurial talent allocation throughout time, we included the number of jinshi degrees per capita during the Ming Dynasty, the number of merchant guilds during the Qing Dynasty, the number of private firms per capita in 2012, and the number of private investors per capita in 2012. To identify whether entrepreneurial talents reflect local culture or simply emerge in a specific setting characterized by a distinct urban environment and advanced state capacity, we included the number of walled cities per province (as a measure of urbanization) during the Ming Dynasty (Chang, 1963) and an index of provincial government efficiency in present times (Chinese National Bureau of Statistics). We used the first available year (1985) for the index to represent the early reform period.

In addition, we seek to differentiate regional entrepreneurial cultures from human capital effects. To make sure that jinshi is not simply a human capital measure, we controlled for both historical levels of education, proxied by the number of lower-level degrees (licentiates) during the Ming Dynasty (Elman, 2013), while modern educational attainment was represented by the per capita number of students enrolled in higher education in 2010.

Finally, we are looking to distinguish whether regional entrepreneurial cultures simply capture colocation and economic agglomeration effects. To do so, our analysis included the distribution of (mostly foreign) banks and factories in China's early industrialization period of the first half of the 20th century, GDP per capita at the outset of reforms in 1978, and the number of SOEs in 2010.

A high value of a loading in the PCA analysis indicates that a variable is closely related to the respective component (dimension). The results of our PCA analysis establish that our data contain two distinct dimensions, with variable loadings as shown in Fig. 4. The first 


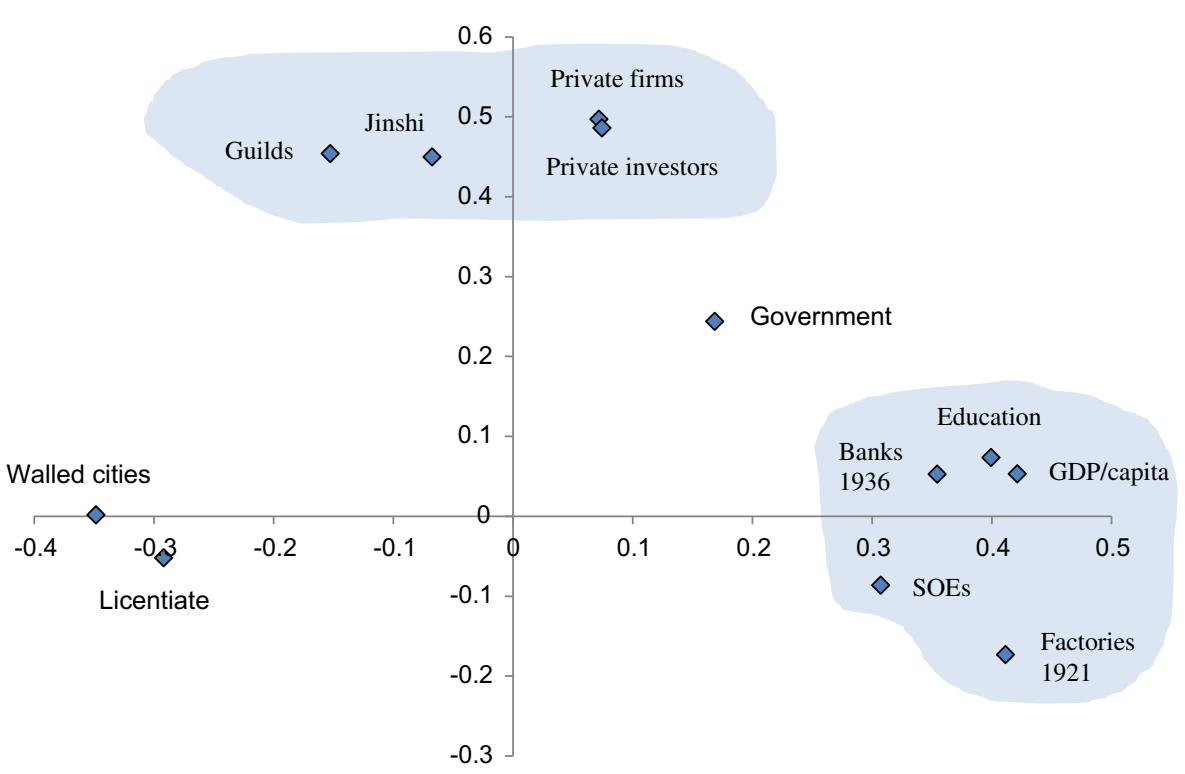

Fig. 4 Principal component loadings. Loadings for the first component are on the $x$-axis and loadings for the second component are on the $y$-axis. The principal components have been rotated using varimax rotation

component, shown on the $x$-axis, reflects modern economic development, with high loadings for 1978 GDP per capita, the number of banks and industrial factories in the first half of the 20th century, the number of students enrolled in higher education, and the number of SOEs in 2010. All measures of modern entrepreneurship are positively correlated with measures of historical and modern economic development; yet the correlation is modest, suggesting that other factors affect private sector development.

We interpret the second component, shown on the $y$-axis, as "entrepreneurial culture," with high loadings for jinshi during the Ming Dynasty, merchant guilds with branch offices in other provinces during the Qing Dynasty, and both measures of modern private entrepreneurship. The close correlation of all four measures throughout time supports the idea that the second component captures an underlying local culture, as in Baumol's definition of "entrepreneurship." Importantly, other firms, such as modern SOEs, commonly linked not with entrepreneurial activities but with public investments, are (weakly) negatively correlated with the second component, lending further support for the claim that entrepreneurial talent allocation reflects cultural traits to a greater extent than general economic factors captured by the first component.

A few other observations are worth noting here too. The measures Ming walled cities and licentiate degrees do not load highly on either component; in particular, these early measures of urbanization and educational attainment are not correlated with the "entrepreneurial" aspect of jinshi and guilds reflected in the second component, suggesting that entrepreneurship today has not been cultivated by early state institutions and is not simply reflecting educational investments or human capital of prior generations. In sum, the PCA results support the view that jinshi and guilds are neither a simple reflection of early levels of civilization or of education. They are also not linked with the economic variables reflected by the first component. 


\section{Panel data estimations}

Table 1 reports the correlations among the variables included in the regression analysis. As expected, the correlations confirm the results from the PCA. All control variables except walled cities and mountains correlate positively with present-day private firms, confirming the expected coevolution of entrepreneurship with regional socioeconomic development. Jinshi and guilds are positively correlated with private firms and investors, while negatively correlated with SOEs, and not correlated with walled cities and GDP per capita in 1978.

We investigated, first, jinshi as an outgrowth of entrepreneurial culture during the Ming Dynasty. The results from the baseline regression are shown in Table 2 (Model 1). Jinshi has a positive effect on the number of private firms at the $5 \%$ significance level, offering some support for the longitudinal stability of underlying entrepreneurial cultures. Foreign cultural influence (FDI) also has a positive effect, as do present (government) and past (water projects) state capacity. A statistical concern here could be that the explanatory variables and the random effects are potentially correlated, which may bias the parameter estimates. In Model 2, we therefore removed the random effects and reestimated the model. The parameter for jinshi is reduced in size compared to Model 1, and is significant at the $1 \%$ level instead of at the $5 \%$ level. The effects of FDI, government, and water projects remain the same in both models. ${ }^{6}$

We then split the sample into the pre-2003 (Model 3) and post-2003 (Model 4) periods to test if changes in legal status affect the link between past and modern forms of entrepreneurial activities. The results show that, in line with our expectations, the association between jinshi and modern entrepreneurship is more important in the later, compared to the earlier, period. The parameter estimate is insignificant in the first period and significant in the second. The parameter estimate also increases in the second period, from .17 to .42 . For FDI, we find the reverse pattern: the parameter estimate is significant in the first period but not in the second period, in line with the interpretation that China's reform and opening policies initially brought greater liberalization for foreign than for indigenous firms. Early state capacity, measured by water projects during the Song Dynasty, has a significant effect in both periods, while modern state capacity is insignificant in both periods according to these results.

To further confirm that jinshi captures a distinct entrepreneurial culture predicting future entrepreneurial talent allocation, rather than being simply a correlate of economic development overall, we replaced the number of private firms with the number of SOEs per capita as the dependent variable (Model 5). Jinshi has no significant effect on these state-owned firms, further supporting the view that private firm development is linked with local entrepreneurial cultures developed and maintained over centuries.

In Table 3, we introduced the interaction terms between jinshi and FDI, and between jinshi and contemporaneous state capacity. However, the inclusion of continuous variables creates a multicollinearity problem. To solve this issue, we replaced FDI and government in the interactions with two dummy variables that take the value of 1 for provinces that have $25 \%$ more FDI and $25 \%$ better bureaucratic quality than the mean. ${ }^{7}$ Including these

\footnotetext{
${ }^{6}$ The similar results between Model 1 and Model 2 indicate that random effects are unnecessary and we are controlling for the important provincial differences with our control variables.

7 The results remain unaffected as long as the cut-off point for the two dummies is between $15 \%$ and $50 \%$ more FDI or improved bureaucratic quality compared to the average province.
} 


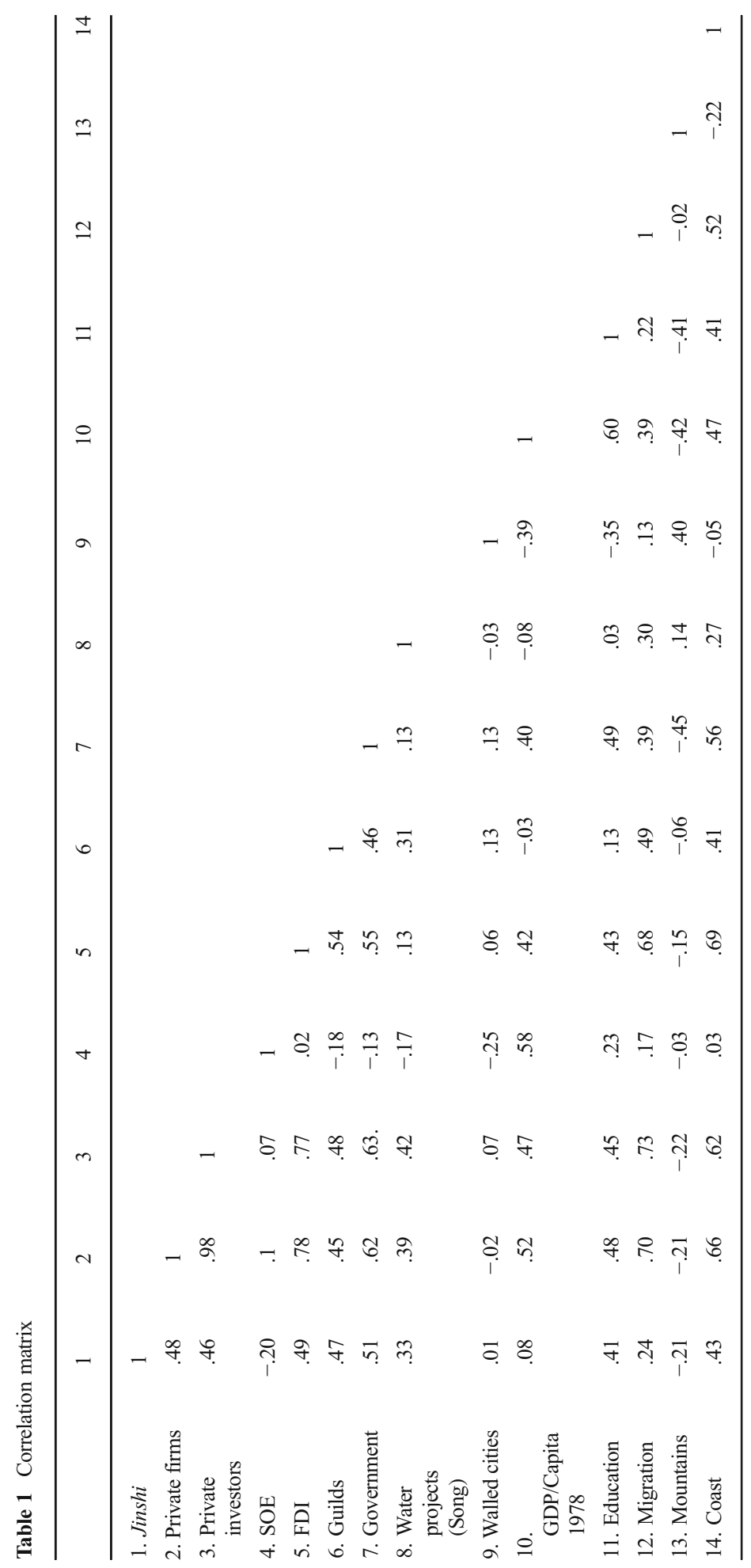




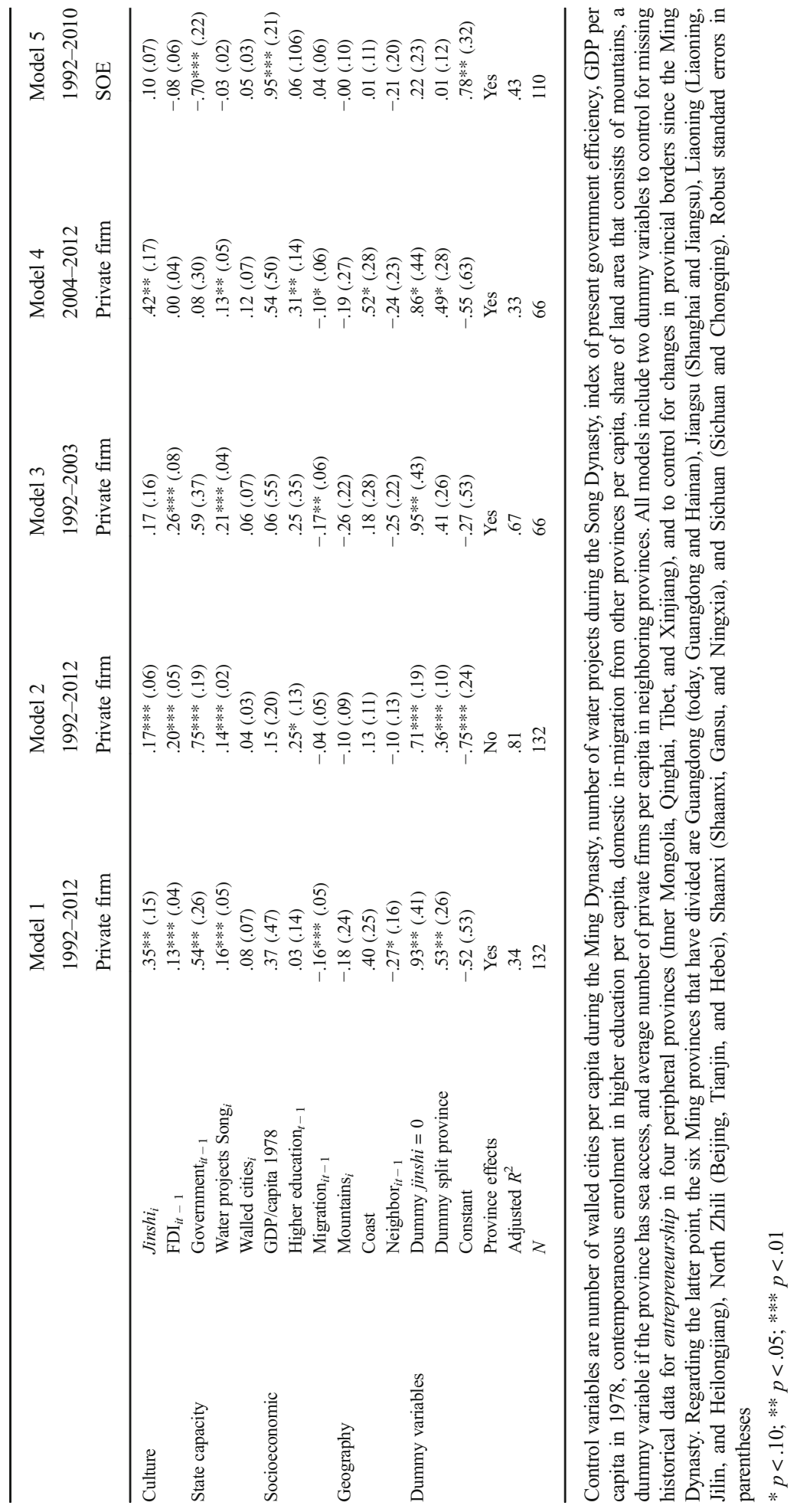




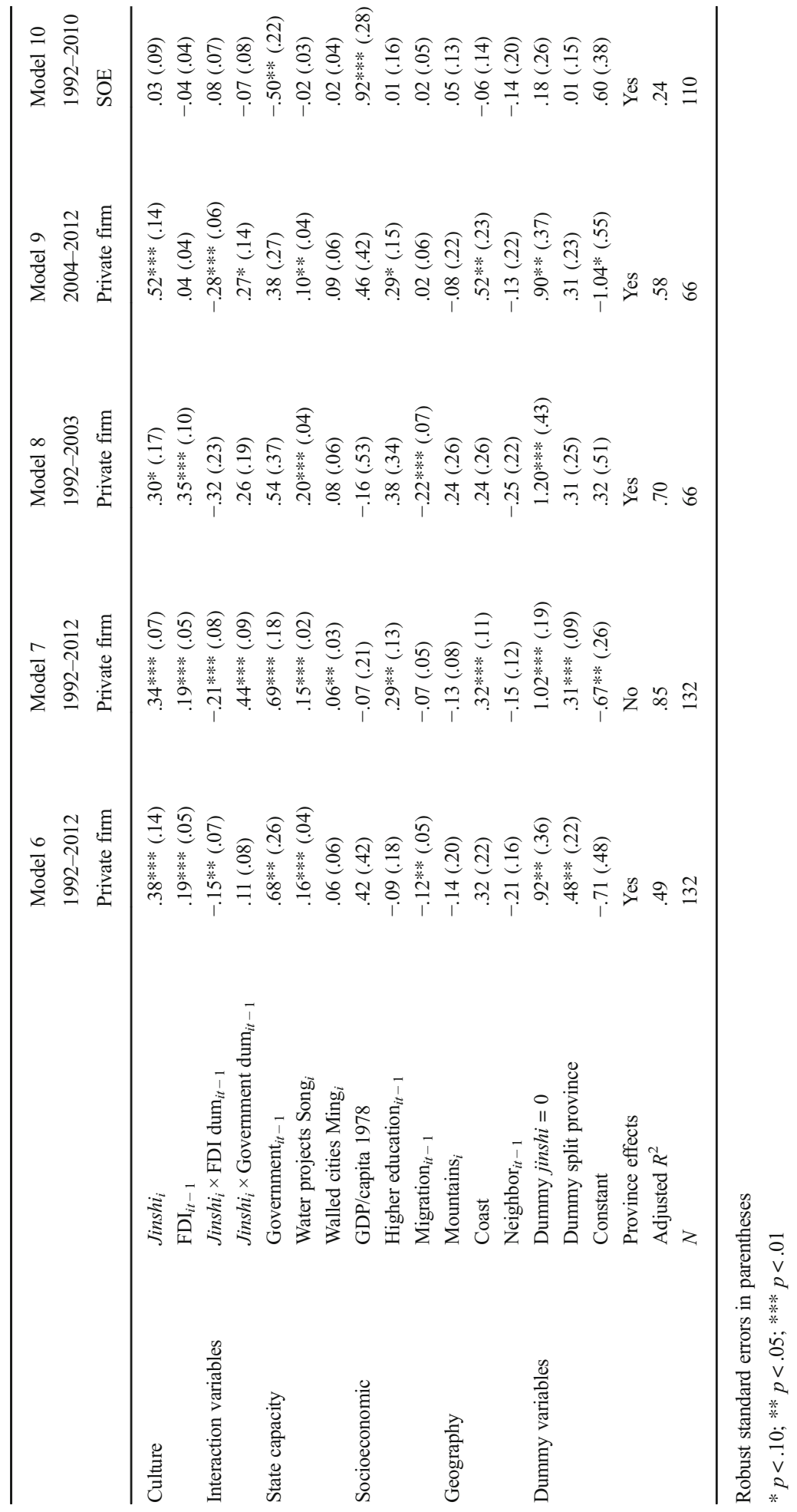


interaction variables does not affect our main conclusion: the direct effect of jinshi remains significant and positive (see Model 6, Table 3).

A difference compared to the results in Table 2 is that jinshi is even significant at the $1 \%$ level, instead of at the $5 \%$ level. The higher significance is caused by the interaction variable between jinshi and FDI, which reduces the effect of prior forms of entrepreneurship, possibly due to intercultural conflicts. These results are also confirmed if we exclude the random effects from the model (Model 7). In contrast, the interaction variable between jinshi and state capacity has no effect on the results (Model 6), and only becomes significant with the exclusion of random effects (Model 7). In this case, the interaction with bureaucratic effectiveness increases the impact of jinshi on private firm allocation.

Splitting the sample once again into two reform periods confirms our previous findings (Table 2, Models 3 and 4). Jinshi is more important in the later period compared to the early period, while FDI matters more in the early period (Models 8 and 9). Our previous results for SOEs are also confirmed. Jinshi has no effect on where SOEs locate (Model 10).

Historical forms of entrepreneurship, foreign exposure, and state capacity are the most important factors explaining the distribution of private firms across the Chinese provinces. The influence of the other explanatory variables varies among the estimated models and depends on model specification and time period. Migration has a negative effect in some models but is usually insignificant. Education enhances private entrepreneurship in two models (Models 2 and 8) but has no effect in the other six. The geographical controls are mostly insignificant. Replacing jinshi with guilds has no major effect on the results. Our results confirm that our proxies of historical measures of entrepreneurship affect the number of private firms (Model 11) but not the number of SOEs (Model 12). The moderating effect of FDI is also preserved when using guilds as an alternative measure (Table 4).

As a robustness check, we replaced private firms as the dependent variable with the number of private investors. In this regression, we used jinshi as the main explanatory variable (Model 13). Once more, our previous results are confirmed. In Model 14, we removed all insignificant variables to avoid over-parameterizing our model. The effect of jinshi remained unaffected.

Most of our time-varying variables have an insignificant effect on private entrepreneurship. We, therefore, re-estimated our models using a simple crosssection instead of a panel data model (see Table 5). Due to the small sample (22 provinces), we only included two control variables that, similar to jinshi, do not have any time variation: we used water projects to represent state capacity and GDP/capita in 1978 to represent socioeconomic development. The parameter for jinshi is close to the estimates in the panel data model: it is insignificant in the early part of the sample and becomes more significant as time progresses, in line with our previous results (Models 15 to 18). Guilds have a stronger effect on private firms in the early part of the sample and a weak effect in the later part, compared to jinsh $i$ (Models 19 and 20). Overall, however, these results support, anew, a robust longitudinal link between the historical outgrowth of regional entrepreneurial and present-day entrepreneurial activities, which suggest an important role of underlying entrepreneurial cultures. 


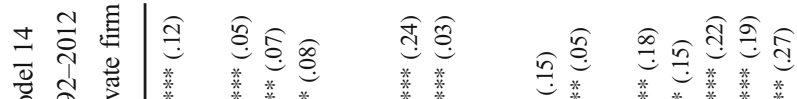

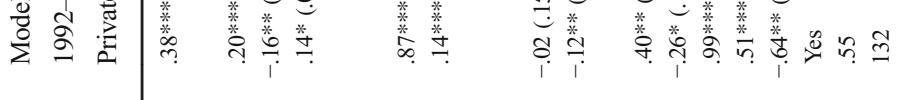

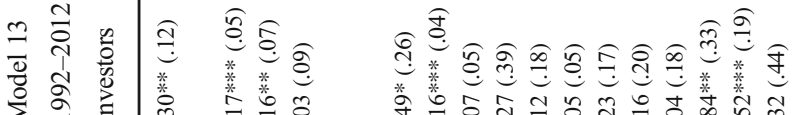

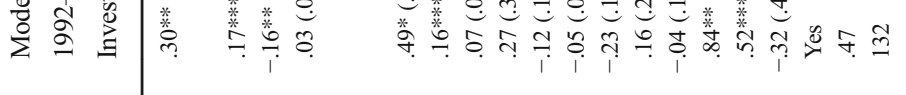

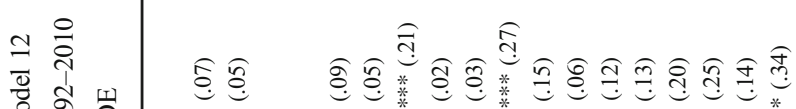

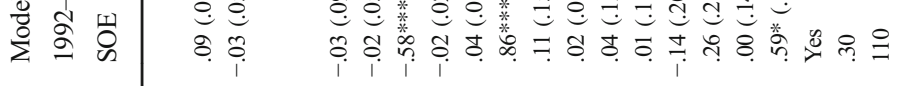

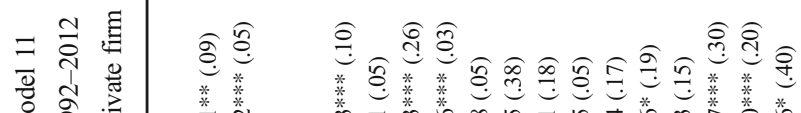

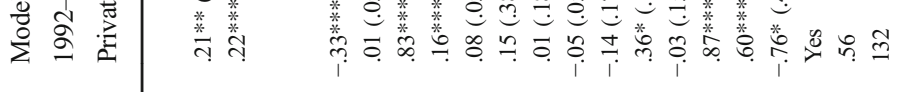

言高

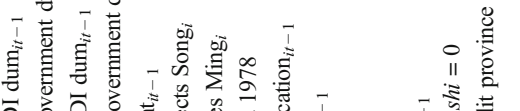

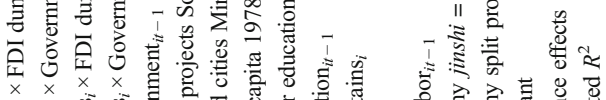

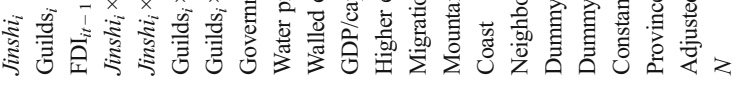

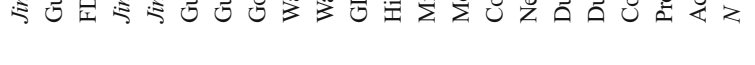




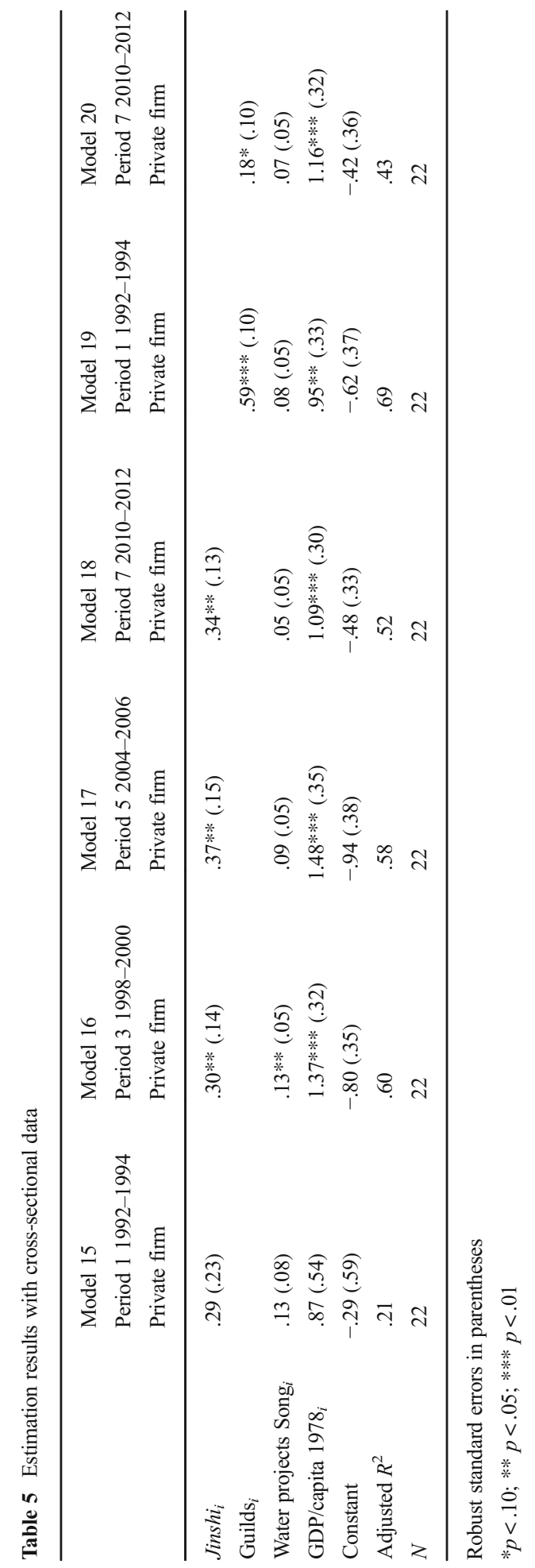




\section{Discussion}

\section{Contributions}

Our contributions are threefold. First, our study contributes to two theoretical strands in the entrepreneurship literature. We offer a long-term test of Baumol's (1990, 2002) theory of entrepreneurial talent allocation, showing that the distribution of local pools of entrepreneurs in China is relatively stable over extended time periods: that is, our results suggest that local entrepreneurial cultures do not only vary in their tendency to spawn entrepreneurs, but that entrepreneurial cultures are also robust over time. This is not to say that institutions do not matter for entrepreneurship, it is well understood that they do (Bruton, Ahlstrom, \& Li, 2010; North, 1990). Rather, our results show that the observed association between historical and current talent distribution is most pronounced once the institutional framework safeguards entrepreneurs and private firm activities and allows for the realization of new profitmaking opportunities (McCloskey, 2010). Our findings also feed into theories of institutional change, which struggle to explain just why bottom-up organizational innovation and renewal is more common in some regions than in others. While earlier work merely alluded to the likely role of local values and traditions in the rise of China's private firm economy (Lardy, 2014; Nee \& Opper, 2012), our study underscores the need for a culturally embedded understanding of development trajectories. These insights are also consistent with recent work by economic historians highlighting the role of social beliefs and societal validation in the rise of economic growth and modern capitalism in the West (McCloskey, 2006, 2010; Mokyr, 2017).

Empirically, the use of historical processes (Ahlstrom, Lamond, \& Ding, 2009) and measures of entrepreneurial activities offers a novel way to study the persistence of entrepreneurial cultures over time. In this context, it is important to note that reliance on historical measures of entrepreneurial talent distribution bypasses some of the common identification problems (Peng et al., 2017). For instance, our historical measures of entrepreneurship (pre-dating the early stages of industrial development) are not open to the interpretation that past economic agglomeration simply breeds agglomeration in the future. Further, we avoid some of the causality concerns raised regarding the use of psychological scores (Hayton et al., 2002) aiming to identify specific personality traits and local cultures (Davidsson \& Wiklund, 1997; Pinillos \& Reyes, 2011; Thomas \& Mueller, 2000).

Finally, our study has several practical implications, specifically for public policy makers but also for private investors. First, our results indicate that formal institutional reforms and pro-business policies are not likely to be sufficient, in the absence of supportive local cultural norms and social beliefs, to sustain a dynamic private firm economy. While we found openness to foreign investment to be important for initial private sector growth, sustaining this growth was dependent on the presence of a strong local entrepreneurial culture, especially the freedom to innovate and operate. These findings also suggest that government efforts to encourage new business ventures - if they are to have more than short-term effects - will need to take into account local cultural norms. Attempts to boost the private sector with massive infusions of infrastructure investments in neglected hinterland regions, for example, such as the establishment of business parks, may prove ineffective in the absence of a local entrepreneurial tradition to actually encourage and manage these firms successfully (Lerner, 2009). Large-scale investment in science and technology parks in China (Watkins-Mathys \& Foster, 2006), for instance, implemented with little 
regard for regional variation in entrepreneurial cultures, often failed to promote indigenous innovation and the formation of new clusters of firms.

\section{Limitations and future research}

While we believe this study provides relatively robust findings supporting the long-term stability of entrepreneurial cultures and the ensuing impact on the allocation of business ventures, the focus on a single country naturally warrants some caution and invites future research. Regional cultures, for instance, may be more stable in China than in countries that have experienced greater immigration or more frequent changes to their political borders (Gong et al., 2011). In China, long-term stability and limited external influence on the political system have left the territorial boundaries fairly stable over several centuries. Further, the society is ethnically highly homogeneous, with limited cultural influences from immigrants (Lynn \& Chang, 2013), or even interprovincial migration (Wen et al., 2004). The limited exposure to external political and cultural influences may also have contributed to the persistence of distinct regional cultures in China.

Confirmation of the long-term stability of the outgrowths of distinct entrepreneurial cultures in different cultural and political contexts is, therefore, essential before drawing any general conclusions. Such work would also allow further exploration of the interplay between cultural values and other components of the institutional environment. An interesting question, for example, is whether cultural stability differs between collectivist and individualist societies (Hofstede, 1980). Given the social transmission of cultural values through group learning, imitation, and selection of favored traits (Richerson \& Boyd, 2005), one could expect cultural stability to be stronger in collectivist than in individualist societies.

Another potential limitation of our study is the time lag between the start of economic reforms in 1978 and the beginning of consistent statistical reporting of private firm registration. We are obviously missing the very early stage of economic reforms, which leaves unanswered the question of how much time cultural dispositions actually need to recover after the conclusion of disruptive political campaigns, such as China's Cultural Revolution. It is, however, noteworthy that the number of private firms in 1992 was less than 140,000 nationwide, compared to almost 11 million in 2012. The limited number of firms and their high concentration in only a few regions before 1992 suggests that a longer time period would have little effect on the results.

Finally, our analysis of cross-cultural interaction effects was, to some extent, guided and limited by the information available on foreign firms at the provincial level. In light of work on the importance of cultural distance in explaining economic outcomes, it could be useful to explore the identity and distance of interacting cultural influences (Wang, Liu, Wei, \& Wang, 2014). It may well be that those provinces receiving foreign investments predominantly from countries regarded as culturally closer realize smaller or no negative interaction with their local entrepreneurial culture. More fine-grained data might offer new insights into the specific processes of cultural interaction.

\section{Conclusion}

Building on Baumol's $(1990,2002)$ theory of entrepreneurial talent allocation, our study explores the stability of regional entrepreneurial cultures over extended periods of time. 
Our results from China confirm that regional entrepreneurial culture is in fact surprisingly stable over decades there, while the form of entrepreneurial activities develops in response to changing institutions and the reevaluation of social beliefs. These results call for stronger recognition of cultural factors in the explanation of encouragement (and discouragement) of entrepreneurial activities. They also suggest the need for closer integration of institutional and cultural explanations of organizational change and renewal. For practitioners, our results hold one important lesson: Well-meant policies and institutional reforms aiming to foster entrepreneurship will be difficult to implement in regions that lack an entrepreneurial culture developed and nurtured over many generations. More research is needed on how to seed and nurture the entrepreneurial traditions that can demonstrate the efficiacy and durability exhibited in the leading entrepreneurial regions of China covered in this study.

Acknowledgments The authors are grateful to the Marianne and Marcus Wallenberg Foundation for support of this work. The authors also thank David Ahlstrom for outstanding editorial guidance.

\section{Appendix}

Table 6 Data sources

\begin{tabular}{ll}
\hline Variable & Data source \\
\hline $\begin{array}{l}\text { Historical data } \\
\text { Jinshi }\end{array}$ & Ho (1962) \\
Licentiates & Elman (2013) \\
Guilds & Moll-Murata (2008) \\
Walled cities & Chang (1963) \\
Number of banks, 1936 & Zhongguo jindai jingji shi \\
Number of factories, 1921 & China Year Book 1921-22 \\
Population, Ming Dynasty & Ho (1962) \\
Population, Qing Dynasty & Ho (1962) \\
Population, Republic & China Year Book 1921-22 \\
Modern data & \\
Private firms & Blue books on private enterprises \\
Private investors & Blue books on private enterprises \\
State-owned firms & China Statistical Yearbook (State Statistical Bureau, various years) \\
Foreign firms & China Statistical Yearbook (State Statistical Bureau, various years) \\
GDP, 1978 & China Statistical Yearbook (State Statistical Bureau, 2010) \\
Population, 1978 & China Statistical Yearbook (State Statistical Bureau, 2010) \\
Migration & Chan (2012) \\
Higher education & China Statistical Yearbook (State Statistical Bureau) \\
\hline
\end{tabular}

Open Access This article is distributed under the terms of the Creative Commons Attribution 4.0 International License (http://creativecommons.org/licenses/by/4.0/), which permits unrestricted use, distribution, and reproduction in any medium, provided you give appropriate credit to the original author(s) and the source, provide a link to the Creative Commons license, and indicate if changes were made. 


\section{References}

Acemoglu, D. 1995. Reward structures and the allocation of talent. European Economic Review, 39: 17-33.

Ahlstrom, D., Lamond, D., \& Ding, Z. 2009. Reexamining some management lessons from military history. Asia Pacific Journal of Management, 26(4): 617-642.

Ahlstrom, D., \& Wang, L. C. 2010. Entrepreneurial capitalism in East Asia: How history matters. In H. Landström, \& F. Lohrke (Eds.). Historical foundations of entrepreneurship research: 406-428. Cheltenham, UK: Edward Elgar.

Ahlstrom, D., Young, M. N., Chan, E. S., \& Bruton, G. D. 2004. Facing constraints to growth? Chinese entrepreneurs and traditional business practices in East Asia. Asia Pacific Journal of Management, 21(3): 263-285.

Ahlstrom, D., Young, M. N., Nair, A., \& Law, P. 2003. Managing the institutional environment: Challenges for foreign firms in post WTO China. SAM Advanced Management Journal, 68(2): 41-49.

Annual report on the non-state-owned economy in China [Zhongguo minying jingji fazhan baogao]. 2015 (And various years). Beijing: Social Sciences Academic Press.

Baumol, W. J. 1990. Entrepreneurship: Productive, unproductive, and destructive. Journal of Political Economy, 98(5): 893-921.

Baumol, W. J. 2002. The free-market innovation machine: Analyzing the growth miracle of capitalism. Princeton: Princeton University Press.

Beugelsdijk, S. 2010. Entrepreneurial culture, regional innovativeness and economic growth. In A. Freytag, \& R. Thurik (Eds.). Entrepreneurship and culture: 129-154. Heidelberg: Springer.

Bruton, G. D., Ahlstrom, D., \& Li, H. L. 2010. Institutional theory and entrepreneurship: Where are we now and where do we need to move in the future? Entrepreneurship: Theory and Practice, 34(3): 421-440.

Chan KW (2012) Migration and development in China: trends, geography and current issues. Migration and Development, 1(2): 187-205.

Chang, S. D. 1963. The historical trend of Chinese urbanization. Annals of the Association of American Geographers, 53: 109-143.

Chua, R. Y. 2013. The costs of ambient cultural disharmony: Indirect intercultural conflicts in social environment undermine creativity. Academy of Management Journal, 56(6): 1545-1577.

Davidsson, P., \& Wiklund, J. 1997. Values, beliefs and regional variations in new firm formation rates. Journal of Economic Psychology, 18: 179-199.

DellaPosta, D., Nee, V., \& Opper, S. 2017. Endogenous dynamics of institutional change. Rationality and Society, 29: 5-48.

Elman, B. A. 2013. Civil examinations and meritocracy in late imperial China. Cambridge: Harvard University Press.

Fritsch, M., \& Wyrwich, M. 2014. The long persistence of regional levels of entrepreneurship: Germany, 1925-2005. Regional Studies, 48(6): 955-973.

Giersch, C. P. 2014. Commerce and empire in the borderlands: How do merchants and trade fit into Qing frontier history? Frontiers of History in China, 9(3): 361-383.

Gong, Y., Chow, I. H.-s., \& Ahlstrom, D. 2011. Cultural diversity in China: Dialect, job embeddedness, and turnover. Asia Pacific Journal of Management, 28(2): 221-238.

Greif, A. 2006. Institutions and the path to the modern economy: Lessons from medieval trade. Cambridge: Cambridge University Press.

Hayton, J. C., George, G., \& Zahra, S. A. 2002. National culture and entrepreneurship: A review of behavioral research. Entrepreneurship: Theory and Practice, 26(4): 33-52.

Ho, P. T. 1962. The ladder of success in imperial China: Aspects of social mobility, 1368-1911. New York: John Wiley \& Sons.

Hofstede, G. 1980. Culture's consequences: International differences in work-related values. Beverly Hills: Sage.

Hoskisson, R. E., Eden, L., Lau, C. M., \& Wright, M. 2000. Strategy in emerging economies. Academy of Management Journal, 43(3): 249-267.

Huo, Y. P., \& Randall, D. M. 1991. Exploring subcultural differences in Hofstede's value survey. The case of the Chinese. Asia Pacific Journal of Management, 8(2): 159-173.

Jiao, L., Harrison, G., Dyball, M. C., \& Chen, J. 2017. CEO values, stakeholder culture, and stakeholder-based performance. Asia Pacific Journal of Management, 34(4): 875-899.

Jolliffe, I. T. 2002. Principal component analysis. New York: Springer.

Kwon, J.-W. 2012. Does China have more than one culture? Exploring regional differences of work values in China. Asia Pacific Journal of Management, 29(1): 79-102. 
Landes, D. S. 1998. The wealth and poverty of nations: Why some are so rich and some so poor. New York: W. W. Norton.

Lardy, N. 2014. Markets over Mao: The rise of private business in China. Washington, DC: Peterson Institute for International Economics.

Lau, C. M., \& Bruton, G. D. 2008. FDI in China: What we know and what we need to study next. Academy of Management Perspectives, 22(4): 30-44.

Lerner, J. 2009. Boulevard of broken dreams: Why public efforts to boost entrepreneurship and venture capital have failed-And what to do about it. Princeton: Princeton University Press.

Liñán, F., \& Fernandez-Serrano, J. 2014. National culture, entrepreneurship and economic development: Different patterns across the European Union. Small Business Economics, 42: 685-701.

Long, C., Yang, J., \& Zhang, J. 2015. Institutional impact of foreign direct investment in China. World Development, 66: 31-48.

Lynn, R., \& Chang, H. 2013. Differences in intelligence across thirty-one regions of China and their economic and demographic correlates. Intelligence, 41: 553-559.

Matthews, J. A. 2017. Dragon multinationals powered by linkage, leverage and learning: A review and development. Asia Pacific Journal of Management, 34(4): 769-775.

McCloskey, D. 2006. The bourgeois virtues: Ethics for an age of commerce. Chicago: University of Chicago Press.

McCloskey, D. 2010. Bourgeois dignity: Why economics can't explain the modern world. Chicago: University of Chicago Press.

Min, M. 2013. The Confucian merchant tradition in the late Qing and the early republic and its contemporary significance. Social Sciences in China, 34(2): 165-183.

Miyazaki, I. 1976. China's examination hell: The civil service examinations of imperial China. New Haven: Yale University Press.

Mokyr, J. 2017. A culture of growth: The origins of the modern economy. Princeton: Princeton University Press.

Moll-Murata, C. 2008. Chinese guilds from the seventeenth to the twentieth centuries: An overview. International Review of Social History, 53: 213-247.

Murphy, K. M., Shleifer, A., \& Vishny, R. W. 1991. The allocation of talent: Implications for growth. The Quarterly Journal of Economics, 106(2): 503-530.

Nee, V., \& Opper, S. 2012. Capitalism from below: Markets and institutional change in China. Cambridge: Harvard University Press.

North, D. C. 1990. Institutions, institutional change and economic performance. Cambridge: Cambridge University Press.

Pagel, M. 2012. Wired for culture: Origins of the human social mind. New York: W. W. Norton.

Peng, M. W., Ahlstrom, D., Carraher, S. M., \& Shi, W. S. 2017. An institution-based view of global IPR history. Journal of International Business Studies, 48(7): 893-907.

Peterson, C., \& Seligman, M. E. P. 2004. Character strengths and virtues: A handbook and classification. New York: Oxford University Press.

Pinillos, M. J., \& Reyes, L. 2011. Relationship between individualist-collectivist culture and entrepreneurial activity: Evidence from global entrepreneurship monitor data. Small Business Economics, 37: 23-37.

Richerson, P. J., \& Boyd, R. 2005. Not by genes alone: How culture transformed human evolution. Chicago: University of Chicago Press.

Richerson, P. J., \& Christiansen, M. H. (Eds.) 2013. Cultural evolution: Society, technology, language, and religion. Cambridge: MIT Press.

Schumpeter, J. A. 1912/1934. The theory of economic development. Cambridge: Harvard University Press.

Shane, S. 1993. Cultural influences on national differences in rates of innovation. Journal of Business Venturing, 8: 59-74.

Shiue, C. H., \& Keller, W. 2007. Markets in China and Europe on the eve of the industrial revolution. American Economic Review, 97(4): 1189-1216.

Singh, K. 2007. The limited relevance of culture to strategy. Asia Pacific Journal of Management, 24(4): 421428.

State Statistical Bureau. 2010. China statistical yearbook. Beijing: Statistical Publishing House.

Steensma, H. K., Marino, L., Weaver, K. M., \& Dickson, P. H. 2000. The influence of national culture on the formation of technology alliances by entrepreneurial firms. Academy of Management Journal, 43(5): 951-973.

Steensma, H. K., Tihanyi, L., Lyle, M. A., \& Dshanaraj, C. 2005. The evolving value of foreign partnerships in transitioning economies. Academy of Management Journal, 48(2): 213-235. 
Sun, S. 2011. Foreign direct investment and technology spillovers in China's manufacturing sector. Chinese Economy, 44(2): 25-42.

Tabellini, G. 2010. Culture and institutions: Economic development in the regions of Europe. Journal of the European Economic Association, 8(4): 677-719.

Thomas, A. S., \& Mueller, S. L. 2000. A case for comparative entrepreneurship: Assessing the relevance of culture. Journal of International Business Studies, 31(2): 287-301.

Turchin, P. 2013. The puzzle of human ultrasociality: How did large-scale complex societies evolve? In P. J. Richerson, \& M. H. Christiansen (Eds.). Cultural evolution: Society, technology, language, and religion: 61-74. Cambridge: MIT Press.

Wang, J., Liu, X. M., Wei, Y. Q., \& Wang, C. G. 2014. Cultural proximity and local firms' catch up with multinational enterprises. World Development, 60: 1-13.

Watkins-Mathys, L., \& Foster, M. J. 2006. Entrepreneurship: The missing ingredient in China's STIPs?. Entrepreneurship and Regional Development, 18: 249-274.

Weber, M. 1904/2006. The Protestant ethic and the spirit of capitalism (T. Parsons, Trans.). New York: Scribner.

Wen, B., Li, H., Lu, D., Song, X., Zhang, F., He, Y., Li, F., Gao, Y., Mao, X., Zhang, L., Qian, J., Tan, J., Jin, J., Huang, W., Deka, R., Su, B., Chakraborty, R., \& Jin, L. 2004. Genetic evidence supports demic diffusion of Han culture. Nature, 431: 302-304.

Whiting, S. H. 2000. Power and wealth in rural China: The political economy of institutional change. Cambridge: Cambridge University Press.

Zelekha, Y., Avnimelech, G., \& Sharabi, E. 2014. Religious institutions and entrepreneurship. Small Business Economics, 42: 747-767.

Sonja Opper ( $\mathrm{PhD}$, Tubingen University) is Gad Rausing Professor of International Economics and Business at the School of Economics and Management at Lund University (Sweden). Her current research focuses on explanations of institutional change, the interplay between networks and institutions, entrepreneurial networks and social heuristics of strategic decisions. Her book Capitalism from Below: Markets and Institutional Change (with Victor Nee) won the George R. Terry Award 2013, awarded by the Academy of Management for the best book in management studies. Her work on China was published in numerous journals including the Academy of Management Journal, Management Science, and Social Networks.

Fredrik N.G. Andersson (PhD, Lund University) is Associate Professor of Macroeconomics at the Lund University School of Economics and Management. Dr. Andersson's research focuses on the importance of formal and informal institutions for long run economic growth, and on understanding the causes of institutional change. His research has been published in journals such as the World Development, Journal of Economic History, and European Review of Economic History. 